\title{
Endoscopic removal of a bladder calculus via flexible sigmoidoscopy
}

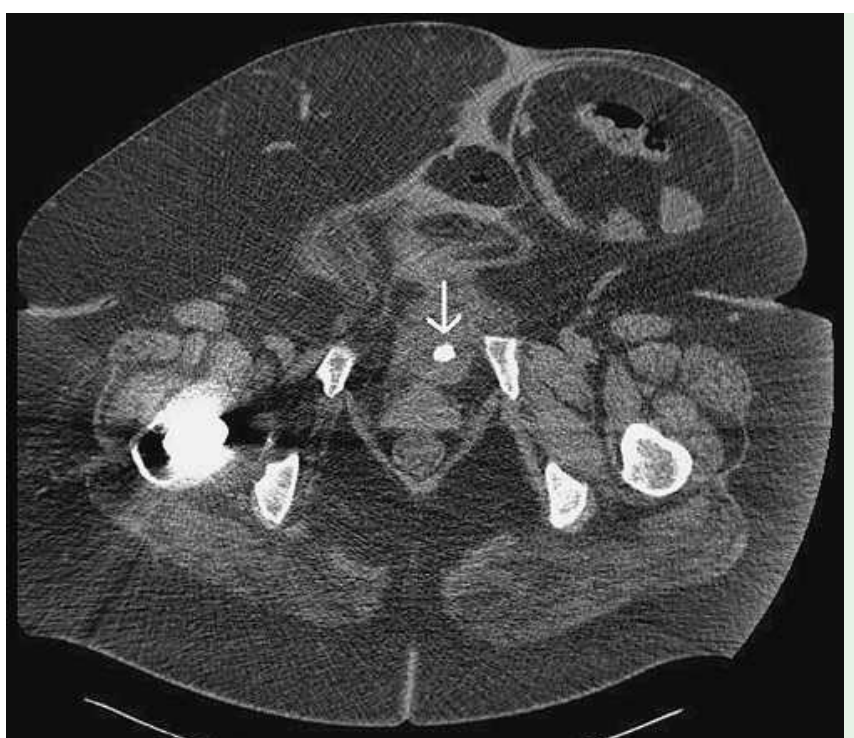

Figure 1 Computed tomographic scan of the pelvis, demonstrating a stone in the urinary bladder (arrow).

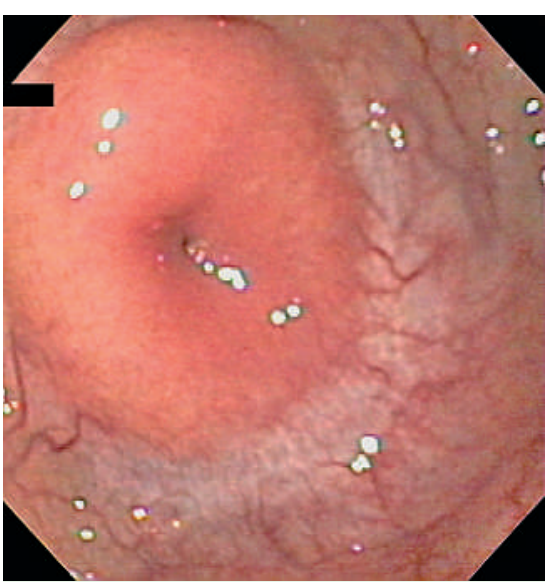

Figure 2 lleocolonic anastamosis identified in the distal sigmoid colon.

A 51-year-old female with a complex urologic history was admitted to our institution with severe, lower midline abdominal pain radiating into the pelvis. She stated that the pain was reminiscent of the pain she experienced with prior bladder calculi.

Her history was significant for epispadias status post multiple attempted reconstructions, which ultimately led to closure of the bladder neck and subsequent urinary bladder-ileum-sigmoid colon anastamosis. This produced a successful continent urinary diversion, but she experienced recurrent urinary tract infections and bladder calculi.

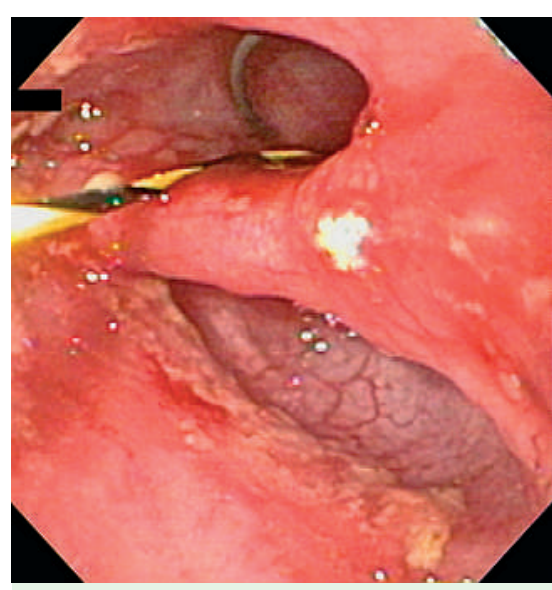

Figure 3 lleocolonic anastamosis following balloon dilation.

On computed tomographic scan of the abdomen and pelvis, a stone was observed in the bladder ( Figure 1 ). Because of her complex surgical history and obesity, a nonsurgical means of stone removal was sought. A gastroenterology consultation was obtained for possible endoscopic removal.

In the operating room under general anesthesia and in the dorsal lithotomy position, a standard upper endoscope was used to perform a flexible sigmoidoscopy. In the distal sigmoid colon, the anastamosis was identified and dilated using a Microvasive ${ }^{\circledR}$ balloon (Boston Scientific, Natick, Massachusetts) over a guide wire ( $\bullet$ Figure 2 and $\bullet$ Figure 3 ). The anasta-

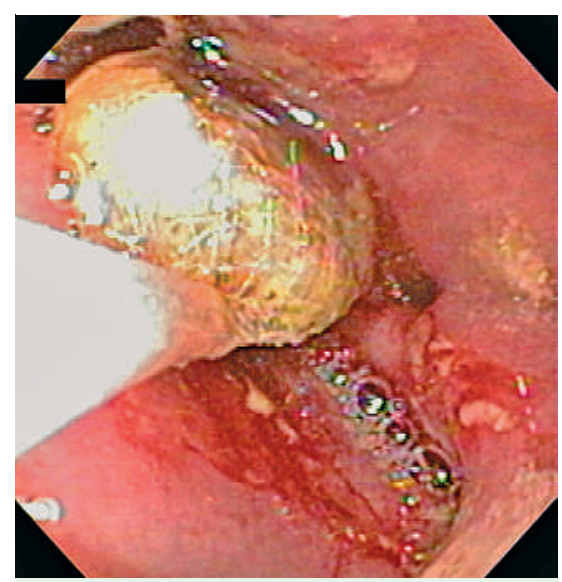

Figure 4 Stone captured with retrieval basket in the urinary bladder.

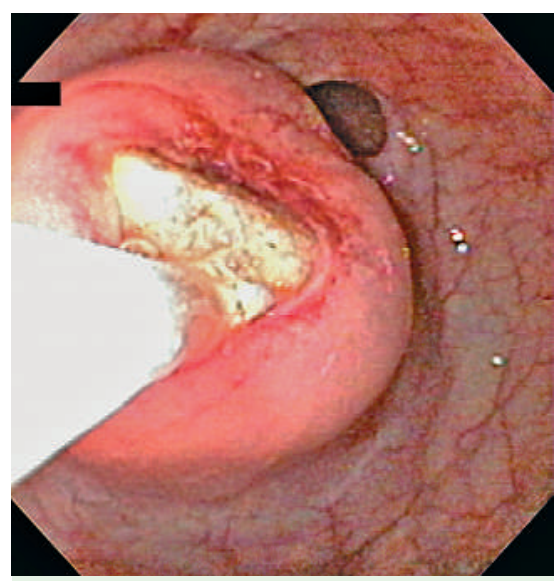

Figure 5 Stone removed through the ileocolonic anastamosis.

mosis was estimated to have a diameter of approximately $6 \mathrm{~mm}$, and was subsequently dilated to $10 \mathrm{~mm}$. Following dilation, the endoscope was advanced through the segment of ileum and into the bladder. In the bladder a $15-\mathrm{mm}$ stone was identified and retrieved ( $\bullet$ Figure 4 and Figure 5) with a Roth $^{\circledR}$ retrieval net (US Endoscopy, Mentor, Ohio). The patient tolerated the procedure well. At 4-month follow-up, the stone had not recurred.

Urinary diversions using a portion of bowel are performed for malignant and benign disorders of the lower genitourinary tract. Gastroenterologists should be familiar with urinary diversions, as some are associated with an increased risk of colorectal adenocarcinoma, such as with ureterosigmoidal anastamoses [1,2]. Despite an exhaustive search of medical and surgical literature, the description of a similar procedure was not found. This case demonstrates the feasibility of removal of a bladder calculus by gastrointestinal endoscopy in a patient with unusual anatomy, and highlights the impor- 
tance of teamwork among specialists in the care of complex patients.

Endoscopy_UCTN_Code_CPL_1AJ_2AI

Endoscopy_UCTN_Code_TTT_1AQ_2AJ

Endoscopy_UCTN_Code_CCL_1AD_2AJ

\section{D. Wells ${ }^{1}$, S. K. Swanson ${ }^{2}$,}

J. K. DiBaise ${ }^{1}$

${ }^{1}$ Division of Gastroenterology \& Hepatology, Mayo Clinic, Scottsdale, Arizona, USA

2 Division of Urology, Mayo Clinic, Scottsdale, Arizona, USA

\section{References}

1 Hurlstone DP, Wells JM, Bhala N, McAlindon $M E$. Ureterosigmoid anastomosis: risk of colorectal cancer and implications for colonoscopists. Gastrointest Endosc 2004; 59 : $248-254$

2 Austen M, Kalble T. Secondary malignancies in different forms of urinary diversion using isolated gut. J Urol 2004; 172: 831 - 838

Bibliography

DOI 10.1055/s-2007-966170

Endoscopy 2007; 39: E117-E118

(C) Georg Thieme Verlag KG Stuttgart · New York .

ISSN 0013-726X
Corresponding author

\section{J. K. DiBaise, MD}

Division of Gastroenterology \& Hepatology

Mayo Clinic

13400 East Shea Boulevard

Scottsdale

AZ 85259

USA

Fax: +1-480-301-8673

dibaise.john@mayo.edu 